\title{
Construction of a New Financial E-Commerce Model for Small and Medium- Sized Enterprise Financing Based on Multiple Linear Logistic Regression
}

Ping Wang, School of Economics and Management, Weifang University of Science and Technology, Shouguang, China Wei Han, Henan Agricultural University, Zhengzhou, China \& Southwest Jiaotong University, Chengdu, China

\begin{abstract}
With the rapid e-commerce economic development, many small and medium-sized enterprises (SMEs) have thrived and aroused increasing attention from the state government. The financing problem of SMEs has naturally become a matter of concern. Under the circumstance, e-commerce finance has opened up new ways for solving financing difficulties faced by SMEs. However, due to the unstable development of SMEs and the imperfect network financing platforms and legal measures, the financing risks of SMEs can hardly be ignored. Given the trend of fast development of e-commerce, many e-commerce enterprises, led by Alibaba, have also been involved in microfinance, leading the trend of the combination of e-commerce finance and creating a new financial model combining e-commerce and microfinance. It is a new and fast way of loan and has mastered comprehensive and rich commercial data and advanced technologies. As a new force in financial systems, microfinance companies have been gradually emerging and growing. The diversified development trend has promoted the solution to the financing difficulties of SMEs. This paper expounds on the development prospects of SMEs and e-commerce finance and illustrates the significance of developing online finance. It also introduces the commonly-used research methods of the two kinds of financial models, such as multiple linear regression method and logistic regression method, and analyzes the reasons for the financing difficulties of SMEs. Currently, the high financing cost is the main reason for the financing difficulties of SMEs. Several reasons account for the high financing cost. Among them, high financing cost, low-efficiency financial system, long financing cycle, and the loan information asymmetry account for $35 \%, 21 \%, 19 \%$, and $25 \%$, respectively. In addition, this paper clarifies the advantages and disadvantages of network finance and the necessity of developing online finance.
\end{abstract}

\section{KEYWORDS}

Electronic Commerce, Financing Issues, Online Finance, Small and Medium-Sized Enterprises

\section{INTRODUCTION}

According to the enterprise market research report, the number of SMEs is huge and play an extremely important role in all businesses. The contribution made by SMEs is even more important, contributing $60 \%$ of the country's gross national product (GNP) annually. Moreover, the annual export volume

DOI: 10.4018/JOEUC.20211101.oa4

This article published as an Open Access article distributed under the terms of the Creative Commons Attribution License (http://creativecommons.org/licenses/by/4.0/) which permits unrestricted use, distribution, and production in any medium, provided the author of the original work and original publication source are properly credited. 
of foreign trade has reached $68.3 \%$ of the national total, and the profits and taxes occupied $52.2 \%$ of the national total (Abe et al., 2015; Xiang \& Worthington, 2017). In addition, SMEs pay more attention to product innovation and patent applications. At present, the number of patent inventions owned by the companies accounts for $65 \%$ of the country.The technological innovation of enterprises reaches $1375 \%$ or more, and it brings $780 \%$ of new products in various fields to society. SMEs have become an important part of the national economy and exerted positive effects on the socialist market economic system, economy, investment, job creations, the rejuvenation of the country through science and education, and taxation (Ann et al., 2019; Oumaya \& Gharbi, 2017). However, the small and medium-sized enterprises suffer from small scale, unstable capital chains, poor management ability, and lack of internal financial data and human allocation information. This leads to non-credit behaviors of financial institutions to SMEs and hinders the development of SMEs, the normal operation and business development. Many enterprises will be unable to obtain financing and lead to capital chain break, resulting in the company out of business or even bankruptcy. Therefore, it is imperative to solve the problem of financing difficulties for SMEs (Bryson \& Daniels, 2015; Sang et al., 2017). E-commerce finance uses Internet technology and information technology to put traditional financial products to the Internet, resulting in a new financial business model that includes capital flow, Internet payments, online investment, and information services. E-commerce finance currently involves seven major formats, namely, Internet payment, equity crowdfunding, e-commerce fund sales, online lending, Internet insurance, Internet trust and Internet consumer finance. With the rapid development of e-commerce finance, these new types of financial business models have gradually replaced the traditional financial model (Hilsenrath \& Pogue, 2017; Khan et al., 2019; Han 2020). The development of e-commerce finance has brought tools, such as big data risk control, for e-commerce financial platform to collect and verify information of SMEs and quantify repayment ability and repayment willingness, so as to reduces the number of SMEs. Information asymmetry greatly controls the bad debt rate of financial institutions.

With the in-depth development of the market economy, the market economy has grown steadily. As an important part of the market economy, SMEs has become more and more crucial and its contribution to finance and social employment has become increasingly important. In stark contrast to the flourishing development of SMEs, the difficulty of financing for enterprises has not been effectively solved, which has seriously affected the further growth of SMEs. As we all know, traditional financial institutions are only willing to lend money to large enterprises with strong capital strength, while SMEs are more difficult to obtain loans. The main reason lies in the unstable SMEs market,unclear development prospects, and lack of credit records and loan collateral. As a result, SMEs have difficulty in obtaining loans and are hard to develop due to the shortage of funds(Dankova \& Telus, 2015; Khashanah \& Alsulaiman, 2016). It is always a difficult problem to solve the problem of SME loan. In recent years, e-commerce microfinance as a financial innovation is booming and has become the focus in e-commerce field. The combination of the Internet and traditional industries has created one miracle after another. The miracle of "Internet + finance" has shaken the monopoly position of the traditional financial system, injected vitality into the financial market, and promoted the development of market diversification. The rise of online financial financing benefits from the boost of the "Internet + Finance" thinking. E-commerce finance is of great significance to the solution to the financing difficulties of SMEs, providing conditions for the reform of traditional financial services. The application of Internet technology not only improves the service quality and efficiency of traditional and non-traditional financial institutions, but also introduces new financial business products, such as mobile payment and $\mathrm{P} 2 \mathrm{P}$ online loan platform. etc. The application of information and communication technology enables the timely release and notification of financial product information to users, and the user's handling of financial services is no longer limited by time and place (Ahn $\&$ Sura, 2020; Chan et al., 2015). In addition, Internet technology can conduct network mining and analysis of SMEs data via various channels, so as to further determine the repayment willingness, repayment ability and credit rating of enterprises in terms of technology, which can greatly reduce 
the information financing symmetry amongst SMEs. The development of new financing models has brought SMEs more abundant financing channels, which not only reduces the financing costs, but also alleviate the lack of collateral and credit guarantee to some extent.

SMEs in Asia are often hailed as the backbone of the economy but SMEs financing has serious difficulties. Banks are the main source of financing for Asian economies. The lack of a comprehensive credit rating database has been the bottleneck for SMEs financing. Yoshino N employed the bank's data on SMEs loans to explore a SMEs credit rating scheme without other financial and non-financial ratios. He used statistical techniques to count five variables in the Thai SMEs sample and classified them according to their financial health. By adopting these technologies, banks could better reduce information asymmetry and set interest rates and loan caps for SMEs. This will ease financing for healthy SMEs and reduce non-performing loans to this important industry (Park, 2018; Rouhani et al., 2018). Brown R studied the role of credit card financing in SMEs and how this role varies with location and business positioning. Using large-scale data sets for SMEs, regression-based analysis shows that companies in the peripheral geographic region use a higher percentage of credit cards than their counterparts in the "core" region. Innovative, growth and export-oriented SMEs are also more inclined to use credit card financing. In addition, SMEs, which use credit cards as an impromptu financial "bootstrap" form, are more likely to seek additional sources of funding in the future (Cheikh-Ammar \& Barki, 2016; Hamidi \& Jahanshahifard, 2018). Wang X used the SMEs of industrial enterprise database as a sample to construct an evaluation index system for financing efficiency of SMEs, including input indicators and output indicators to reflect the financing efficiency of SMEs. Then, the data envelopment analysis method was used to measure the financing efficiency of SMEs, and the results were analyzed by province, industry and ownership. The results show that the overall financing efficiency of SMEs is not high, only 0.445 and half of the financing efficiency of enterprises is lower than 0.429 , lower than the average of $0.445 .95 \%$ of the financing efficiency of enterprises is lower than 0.643 . Among the top $1 \%$ of enterprises with the highest financing efficiency, the number of individual holding companies is the largest, and the state-owned and foreign-funded enterprises are the least. E-commerce is a technological innovation that enables small and mediumsized enterprises to compete on the same level as larger companies. It has the potential to increase efficiency and productivity in many areas and is therefore highly valued by many countries around the world (Dong \& Huo, 2017; Wang et al., 2017). After in-depth analysis of the impact of the Internet and e-commerce on business, industry and the economy, Strzębicki D believed that it is necessary to distinguish the hype from reality. Some researchers have called for a link between the perceptions of e-commerce in developing countries and the barriers to e-commerce. However, there are records that SMEs around the world face major challenges that undermine their ability to function and make the best contribution to their respective economies (Strzębicki, 2015; Yoon \& Occeña, 2015).

This paper introduces the commonly used research methods of the two kinds of financial models, such as multiple linear regression method and logistic regression method, and analyzes the reasons for the financing difficulties of SMEs. The high financing cost is the main reason for the financing difficulties of SMEs, which is caused by high financing costs, financial system hindrance, long financing cycle and asymmetric loan information. In addition, this paper also analyzes the advantages and disadvantages of network finance, and the necessity of developing online finance. The advantages of network finance are time-efficient, low-cost, and information superiority whilethe shortcomings are inadequate supervision, high risk of default, market confusion and other reasons. 


\section{PROPOSED METHOD}

\subsection{Multiple Linear Regression Method}

\subsubsection{Introduction to the Principle}

Multiple linear regression is a commonly used linear regression model. The model contains multiple explanatory variables whose parameters are linear (Chen et al., 2017; Khanmohammadi et al., 2017). A linear regression model with $\mathrm{k}$ explanatory variables can usually be written:

$$
y_{t}=\beta_{0}+\beta_{1} x_{1 t}+\beta_{2} x_{2 t}+\ldots+\beta_{k} x_{k t}+\varepsilon_{t}(t=1,2, \ldots, n)
$$

Multiple linear regression models expressed in matrix form can be written as:

$$
Y=X B+E
$$

among them:

$$
\begin{aligned}
& Y=\left[\begin{array}{c}
y_{1} \\
\cdots \\
y_{2} \\
\vdots \\
y_{n}
\end{array}\right]_{n \times 1} \quad X=\left[\begin{array}{ccccc}
1 & x_{11} & x_{21} & \cdots & x_{k 1} \\
1 & x_{12} & x_{22} & \cdots & x_{k 2} \\
\vdots & \vdots & \vdots & \ddots & \vdots \\
1 & x_{1 n} & x_{2 n} & \cdots & x_{k n}
\end{array}\right]_{n x(k+1)} \\
& B=\left[\begin{array}{c}
\beta_{1} \\
\beta_{2} \\
\vdots \\
\beta_{k}
\end{array}\right]_{(k+1) \times 1} \quad E=\left[\begin{array}{c}
\varepsilon_{1} \\
\varepsilon_{2} \\
\vdots \\
\varepsilon_{3}
\end{array}\right]_{n \times 1}
\end{aligned}
$$

\subsubsection{Model Assumptions}

The classical multiple linear regression model contains the following assumptions: there is no autocorrelation among random error terms, zero mean and same variance, and multivariate normal distribution (Pahlavan et al., 2018):

$$
E(E)=0=\left[\begin{array}{c}
0 \\
\vdots \\
0
\end{array}\right]_{n \times 1}
$$


$\operatorname{Var}(E)=E\left(E E^{\prime}\right)=\sigma^{2} I=\sigma^{2}\left[\begin{array}{cccc}1 & 0 & \cdots & 0 \\ 0 & 1 & \cdots & 0 \\ \vdots & \vdots & \ddots & \vdots \\ 0 & 0 & \cdots & 1\end{array}\right]$

$E \sim N\left(0, \sigma^{2} I\right)$

Interpret the wireless relationship between variables, i.e.:

$\gamma\left(X^{\prime} X\right)=\gamma(X)=k+1$

Among them, the explanatory variable matrix is full rank.

The explanatory variable is not related to the random error, i.e.:

$\operatorname{cov}\left(X^{\prime} E\right)=0$

Explain that the variable is not random, i.e. $n \rightarrow \infty$ at the time:

$n^{-1} X^{\prime} X \rightarrow Q$

where $\mathrm{Q}$ is a finite value non-degenerate matrix.

\subsubsection{Model Parameter Estimation}

Under the condition of satisfying the above four hypotheses, the multiple linear regression model can still estimate the model parameters by least squares method. The least squares estimation is the optimal linear estimation and has unbiasedness (the estimated parameters are parameter values). Unbiased estimation), validity (estimated value is the smallest among all linear unbiased estimators of the parameter values) and linearity (the estimated parameter is a linear function of the interpreted variable) (Ennouri et al., 2017; Piña-Monarrez \& Ortiz-Yañez, 2015).

Assuming the estimated parameters of the model, the estimated value of the explanatory variable is:

$$
\begin{aligned}
& \hat{y}_{t}=\hat{\beta}_{0}+\hat{\beta}_{1} x_{1 t}+\hat{\beta}_{2} x_{2 t}+\ldots+\hat{\beta}_{k} x_{k t}+\varepsilon_{t}(t=1,2, \ldots, n) \\
& \hat{Y}=X \hat{B}
\end{aligned}
$$

Sum of residuals: 


$$
Q=\sum_{t=1}^{n} e_{t}^{2}=\sum_{t=1}^{n}\left(y_{t}-\hat{y}_{t}\right)^{2}=e^{\prime} e=(Y-X \hat{B})^{\prime}(Y-X \hat{B})
$$

among them:

$$
e=\left[\begin{array}{c}
e_{1} \\
e_{2} \\
\vdots \\
e_{k}
\end{array}\right]_{n \times 1}
$$

Solving by least squares:

$$
\begin{aligned}
& \frac{\partial Q}{\partial \hat{B}}=\frac{\partial}{\partial \hat{B}}(Y-X \hat{B})^{\prime}(Y-X \hat{B})=0 \\
& \Rightarrow \frac{\partial}{\partial \hat{B}}\left(Y^{\prime} Y-B^{\prime} X^{\prime} Y-Y^{\prime} X B+B^{\prime} X^{\prime} X B\right)=0 \\
& \Rightarrow-X^{\prime} Y+X^{\prime} X B=0 \\
& \Rightarrow X^{\prime} Y=X^{\prime} X B
\end{aligned}
$$

The ordinary least squares estimate of the available model is:

$$
\hat{B}_{O L S}=\left(X^{\prime} X\right)^{-1} X^{\prime} Y
$$

The estimated value of the variance of the random error term is:

$$
\partial^{2}=\frac{e^{\prime} e}{n-(k+1)}
$$

\subsection{Logistics Regression Method}

\subsubsection{Introduction to the Principle}

The Logistics regression method is often referred to as the binary regression method. In the general economic model, the explanatory variables are usually continuous variables, but in some special practical problems, the interpreted variables are $\{0,1\}$ binary variables. For example, in medical examples, the interpreted variables are usually treated by patients. In the final state, there are only two options for survival or death. For some questionnaires, the explanatory variables are usually 'yes' or 'no' (Mansouri et al., 2016). For this type of problem, the general regression method becomes less suitable. If the general linear regression returns to $\{0,1\}$, the continuous fitting result will be obtained. Provided the variable is greater than 1 or less than 0 , it becomes meaningless and fit. The result is also of little significance between 0 and 1, especially when the fitting result is around 0.5 . For the presentproblem, the Logistics model is more effective (Fügener et al., 2015). The basic principle is briefly described as follows. 
More attention should be paid to the probability of the occurrence of explanatory variables in binary linear models, i.e.:

$$
P(y=1 \mid x)=E(y \mid x)=F\left(\beta_{0}+\sum_{i=1}^{k} \beta_{i} x_{i}\right)=F(z)
$$

In the above formula, we let the probability that the interpreted variable $Y$ occurs as the function $F(z)$ of the linear combination $z$ of the independent variable. For the function $F(z)$, we need it to be a probability cumulative distribution function, so that the function value is between a $(0,1)$ probably (Guo-liang, 2017). In the Logistics model:

$$
F(z)=\frac{\exp (z)}{1+\exp (z)}
$$

\subsubsection{Model Parameter Estimation}

The maximum likelihood estimation method is used (Cunningham et al., 2015):

$$
P\left\{Y_{i}=1 \mid X_{i}\right\}=F\left(Z_{i}\right)=\frac{\exp \left(z_{i}\right)}{1+\exp \left(z_{i}\right)}
$$

among them:

$$
z_{i}=\beta_{0}+\sum_{j=1}^{k} \beta_{j} x_{i j}
$$

A linear combination of the $i$ samples. For all samples, the likelihood function is:

$$
\ln L(\beta)=\sum_{i=1}^{n} Y_{i} \ln F\left(X_{i}^{\prime} \beta\right)+\sum_{i=1}^{n}\left(1-Y_{i}\right) \ln \left(1-F\left(X_{i}^{\prime} \beta\right)\right)
$$

Finding the parameter $\beta$ that maximizes the above function is the parameter estimation of the maximum likelihood estimation:

$$
\frac{\partial \ln L(\beta)}{\partial \beta}=\sum_{i=1}^{n}\left[\frac{Y_{i}-F\left(X_{i}^{\prime} \beta\right)}{F\left(X_{i}^{\prime} \beta\right)\left(1-F\left(X_{i}^{\prime} \beta\right)\right)} f\left(X_{i}^{\prime} \beta\right)\right] X_{i}=0
$$

It is necessary to assume that the second derivative matrix is a negative definite matrix (assuming that the independent variable has no multicollinearity), which guarantees the iterative convergence of the global likelihood function of the maximum likelihood function (Liu \& Zhang, 2017). 


\subsection{E-Commerce Finance}

\subsubsection{Network Financial Characteristics}

In essence, online finance is the integration of traditional financial and Internet technologies with big data. It is the transformation of financial products, businesses, organizations and services anda breakthrough in thetime, region, and service groups of traditional finance. Business models, trading methods, access to information, and payment of funds have all been reformed. Compared with traditional finance, the characteristics of online finance can be concluded as follows.

The first is the low cost. SMEs do not need to go to financial institutions to apply for loans in person. In contrast, they could successfully acquire loans in the network financial model by operating on the system platform to register and submit relevant materials, which not only reduces complicated manual operations, but also reduces financing costs and time costs. For financial institutions, the labor cost is reduced. The types of financing services and simple business operations greatly reduce the investment cost, which attracts more SMEs and achieves a win-win situation.

The second is high efficiency. On the one hand, the online financial business has greatly improved the speed of publicity of financial services through the transmission of information on the Internet. It is processed by computer process standards so that business processing speed is fast. On the other hand, mobile payment under the network finance enables the user to apply for the payment of the goods or services consumed by the mobile phone, and the mobile payment represented by the third-party payment enables the person to complete the payment anytime and anywhere. Then, there will be a high degree of information sharing. Moreover, online financial platformsapply big-data technology to collect information from such channels, obtain information from SMEs, conduct indepth analysis, and evaluate the credit rating of enterprises, so that the information of both parties is relatively transparent in financial activities and the information asymmetry is reduced. In addition, by adding the credit information, it can greatly improve the punishment constraints on financing parties and reduce the repayment rate of enterprises.

Besides, online finance has the advantage of wide coverage. With the use of network and information and communication technologies, financial business processing is no longer limited by time and place. Once the financial business is released, it can quickly informusers, and business operations can be handled anytime and anywhere. The technical framework of the Internet financial platform is shown in Figure 1.

\subsubsection{The Development of Internet Finance}

In 2014, the Chinese government first proposed Internet Finance which attracted great attention of the society, and Internet Finance platforms emerged in a frenzy. Due to the lack of clear department supervision, there were many violations and risk problems in Internet finance. Taking Internet lending as an example, the number of Internet lending platforms decreased by more than 2000 between 2015 and 2016, of which the number of running platforms accounted for a large proportion, up to $29 \%$, reaching 1168. With a series of macro-control policies issued by the state in the recent two years, the current network financial industry has already transitted from barbaric development to standardization, transparency and stability.

Mobile payment in the Internet payment industry is developing rapidly. In 2017, non-cash payment accounts for more than $70 \%$ of the total payments, among which the scale of third-party mobile payment is growing rapidly, with the transaction scaleachieving a year-on-year increase of $68 \%$,reaching 98 trillion. From the perspective of mobile payment users, there are 360 million payroll usersand 900 million WeChat payment users. The huge user base enables the payment services from banks, third-party payment, UnionPay and merchants and other partiesto precipitate a large amount of high-frequency payment data. Furthermore, the development of Internet Securities mode is stable. With the help of new securities companies in Internet exhibition industry, business lines of traditional securities companies benefit from information services,stock speculation tools and community 


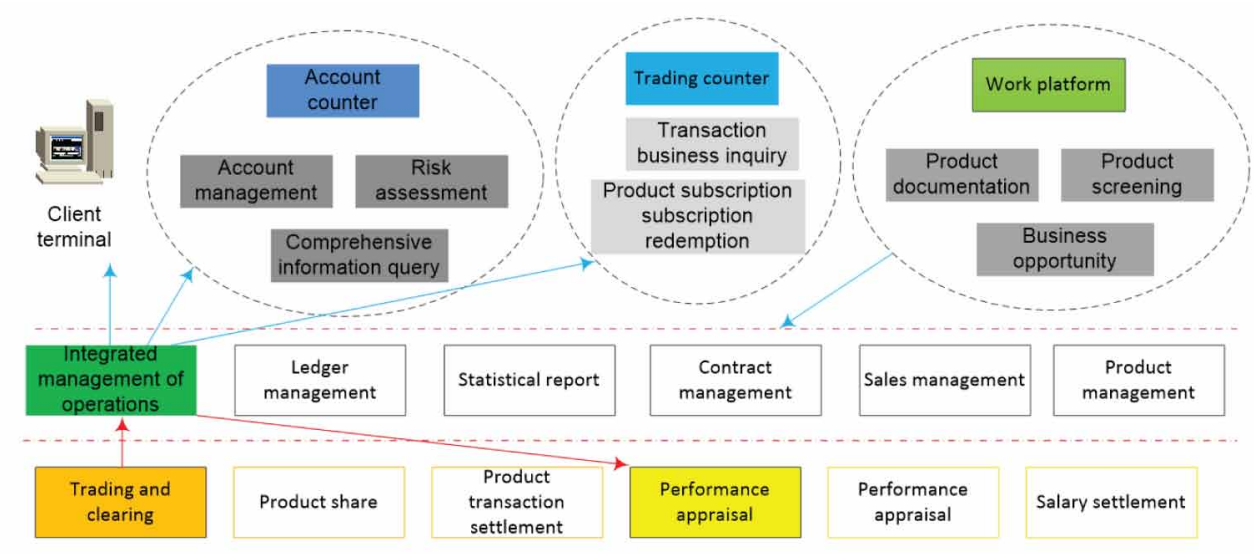

applications. Besides, the third-party fund sales agencies grew rapidly. By the end of 2017, among over 380 fund sales agencies, there have been 118 third-party sales platforms including banks, securities companies, futures and independent third-party platforms. In terms of Internet banking, on the one hand, traditional banks have set up their internet platforms, and their business models have changed greatly in the past.On the other hand, Internet companies have established private banks, with more than 20 approved, such as WeChat banks set up by Tencent, online banks set up by Ali, etc. In the Internet insurance industry, as of the first half of 2017, there have been 130 insurance institutions operating Internet insurance business. Most traditional insurance companies have carried out Internet business through self-built websites or cooperation with third-party platforms, and the scale of Internet scrap has continued to increase. Internet consumer finance is in a high-speed development stage, and there is a huge space for the consumer credit market. As of October 2017, the balance of short-term consumer loans of residents reached 6.54 trillion yuan, and there is still a lot of room for improvement. At present, many Internet companies, P2P network loan platforms and small loan companies are actively participating in consumer finance. Figure 2 shows a schematic diagram of SME financing operations.

\section{EXPERIMENTS}

\subsection{Source and Arrangement of Sample Data}

\subsubsection{Data Source}

The selected data come from the wind database and the basic data of the listed companies of the national SMEs share transfer system. The National Small and Medium Enterprise Share Transfer System, commonly known as the "New Third Board", and the local equity trading center form a prosperous over-the-counter trading platform, which are institutions that provide services for SMEs equity financing. The samples include more than 5,800 companies listed on the New Third Boardas of December 31, 2015, including more than 200 companies in the two networks and delisting companies. A total of 43 different types of indicators are selected, where the code, name, and stock abbreviation constituted the sample ID and were regarded as an indicator).

\subsubsection{Selection of Indicators}

The criteria for selecting indicators are mainly based on the following aspects. First, the asset-liability ratio was selected as the explanatory variable of the multiple linear regression model to measure its 
Figure 2. Schematic diagram of SME financing operations

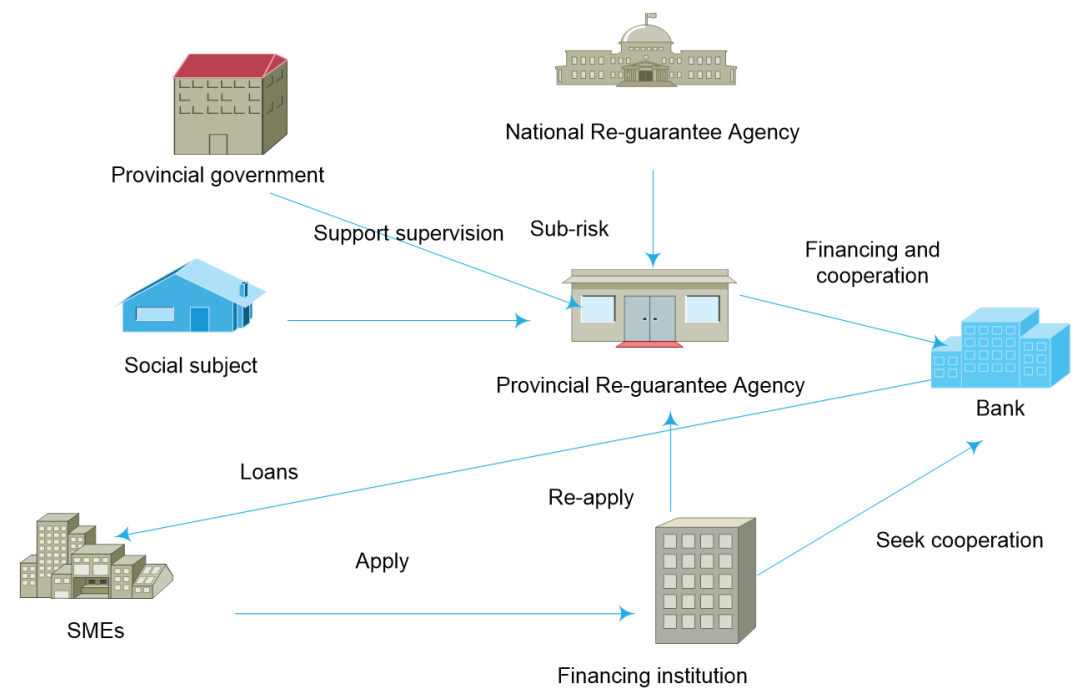

financing ability. The higher the gearing ratio and the stronger the financing ability were, the lower the capitalization capacity and the lower the financing capacity would be. Secondly, for the explanatory variables, we mainly considered several factors that affect the financing ability of the enterprise, including the scale, operational capability, profitability, risk resistance, growth of the company. We also took into consideration the basic situation of the company, including regional and listed industries, as well as the park, the equity transfer method of the company, and the industry of the company.

\subsubsection{Data Cleaning}

The raw data are necessary to be cleaned after the data are obtained. First, the asset-liability ratio of explanatory variables was investigated, and it was found that only 248 of the more than 5,800 samples were not defaulted data, most of which were thereby screened out. Second, certain indicators were removed by default, such as net inflows, inflows, asset-liability ratios, asset-liability ratios after the removal of advances, current assets/total assets, current liabilities ratio, non-current assets/total assets, tangible assets/ total assets, current liabilities/liabilities total, current ratio, quick ratio, cash ratio, cash generated from operating activities, net amount/liabilities total, net cash flow from operating activities/current liabilities, cash flow from operating activities Net/net debt, business cycle, inventory turnover days, inventory turnover, total asset turnover, return on equity, ROE, equity multiplier (DuPont analysis), total asset turnover ratio, etc. Thirdly, the virtual variables were assigned to the categorical variables such as the listed park, the transfer method, the company attribute, the province, and the industry name of the CSRC. They are all expressed in natural numbers. After that, the sample data after preliminary cleaning were obtained.

\subsubsection{Screening of Sample Data}

For the normalized data, it can be found that the sample data contains significant extreme values by the scatter plot between the explanatory variable and each interpreted variable. In order to eliminate the influence of extreme values on the fitting result, the inclusion of extreme values was considered. 


\subsection{Demand Analysis}

Under such an optimistic situation, the small and micro enterprises of the network have encountered a major bottleneck in the process of continuous growth, that is, the strong demand for financing that we are unable to satisfy. First of all, the bank's traditional mortgage-backed loan model contradicts the actual situation of small and micro enterprises. Most of the suppliers on the e-commerce platform are small in scale. They have few assets, lack the collateral required for traditional credit, and cannot obtain third-party guarantees. In the process of applying for loans from banks, credit records and credit evaluation have become a major problem. In particular, in the past two years, banks have tightened monetary policy under the state's macroeconomic regulation and control, reducing the scale of credit, making it difficult for small and micro enterprises to obtain loans from banks. Secondly, based on the characteristics of the industry, Small and micro enterprises have relatively low production and operation costs on most e-commerce platforms and require less working capital. Some loans are only limited to a few thousand yuan, so the loan amount is too low. The relatively frequent number of loans brings low returns and high risks to banks, so some banks are reluctant to engage in such microfinance business. Moreover, the micro-enterprise of the network business has a high frequency of borrowing and high demand for the turnover rate of funds. As a result, the traditional credit business cannot meet its requirements. The growing financing needs of small and micro enterprises in the field of e-commerce are not compatible with traditional bank credits, making it difficult to balance the supply and demand of microfinance funds, so the financing gap needs to be filled. At this time, the rise of e-commerce microfinance has adapted to the market demand and opened up a new path for solving the financing difficulties of small and micro enterprises, whichsatisfy the needs of economic development in the network era and has a broad space for development.

\section{DISCUSSION}

\subsection{Analysis on the Causes of Financing Difficulties of Small and Medium-Sized Enterprises}

With the in-depth development of market economy, the main body of market economy is growing. As an important part of market economy, small and medium-sized enterprises is becoming prominently important, and increasingly contributes to finance, social employment and other aspects. In contrast with the vigorous development of small and medium-sized enterprises, the financing problem of enterprises has not been effectively solved, which has seriously affected the further expansion of small and medium-sized enterprises. We analyzed and discussed the causes of financing difficulties among small and medium-sized enterprises. The results are shown in Figure 3.

From Figure 3, we can see that the causes of SMEs' financing difficulties can be roughly divided into four categories: financial system obstruction, high financing cost, long financing cycle and asymmetric loan information. Among these four reasons, financial system obstruction, high financing cost, long financing cycle and the asymmetry of loan information accounts for 35\%, 19\%, $25 \%$ and $21 \%$ respectively. The bank loans are the main way of enterprise financing, but the bank's examination of the loan application is very strict, which leads to many small and medium-sized enterprises unable to loan in the bank, and the small and medium-sized enterprise financing itself is characterized by a small amount of capital and multiple times, so it causes the high cost and long cycle of small and medium-sized enterprises' loan from the bank. In addition, the information of many small and medium-sized enterprises is not complete, which also hinders the financing of small and medium-sized enterprises.

\subsection{Financing Availability Index}

The dynamic database of small and medium-sized enterprises is a database designed to dynamically monitor the prosperity of small and medium-sized enterprises, and more than 10000 small and SMEs 


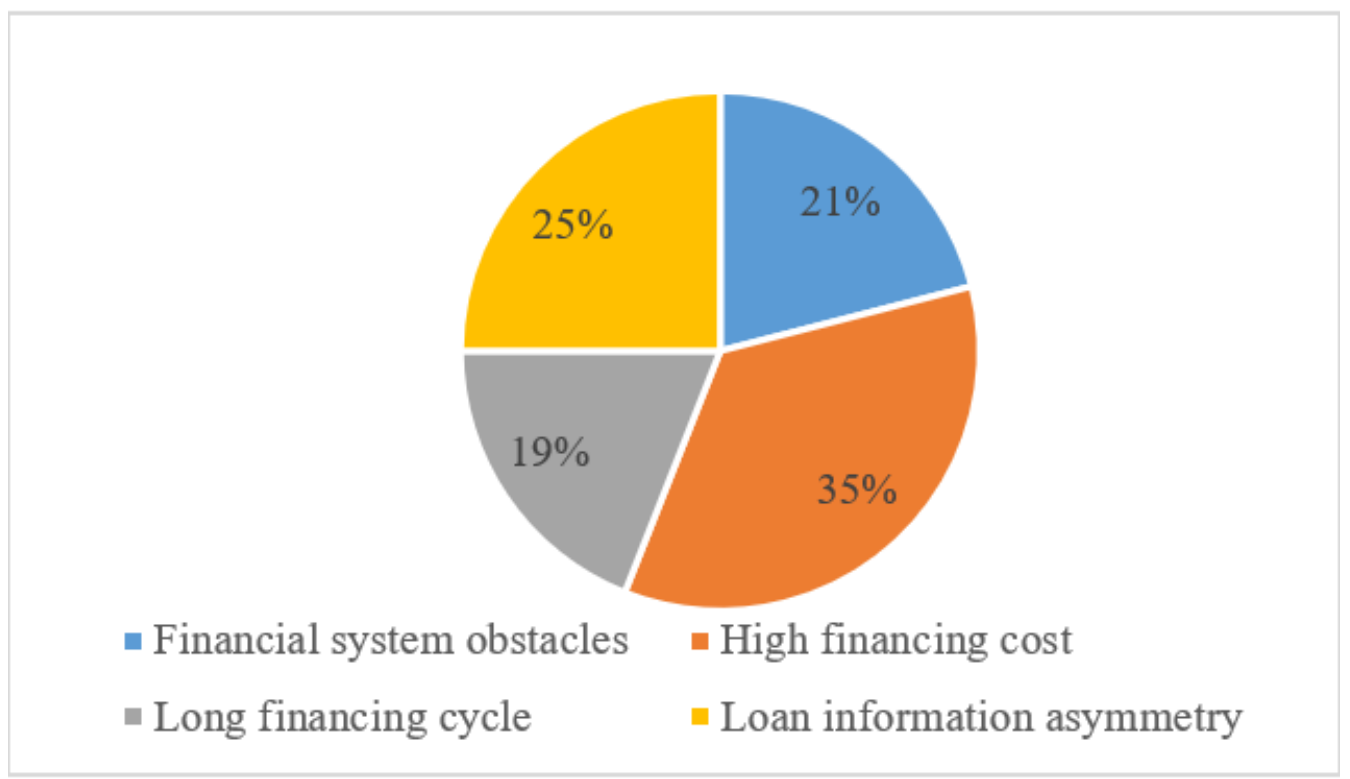

are invited to enter the monitoring system to fill in the data, so as to better track the operation and development of small and medium-sized enterprises. The disclosed enterprise questionnaire survey data well shows the operation and development status of more than 10000selectedmedium and small enterprises. In the "financing difficult" option, four options are set:"easy", "general", "difficult" and "no financing demand". This paper selects the data of 10,000 SMEs from June 2015 to December 2018 , in which the data passed the consistency test of 6,432 enterprises, a total of 52,256 data samples. The data results are shown in Figure 4.

As can be seen from Figure 4, from 2015 to 2018, the absolute number of SME financing is increasing, from an average of 4.48 in 2015 (unit: 100,000) to 18.5 in 2018 (unit: 100,000), indicating that the development of business and the financing environment of small and medium-sized e-commerce enterpises are constantly improving.Especially in June 2018, corporate financing has

Figure 4. Corporate financing number and time relationship

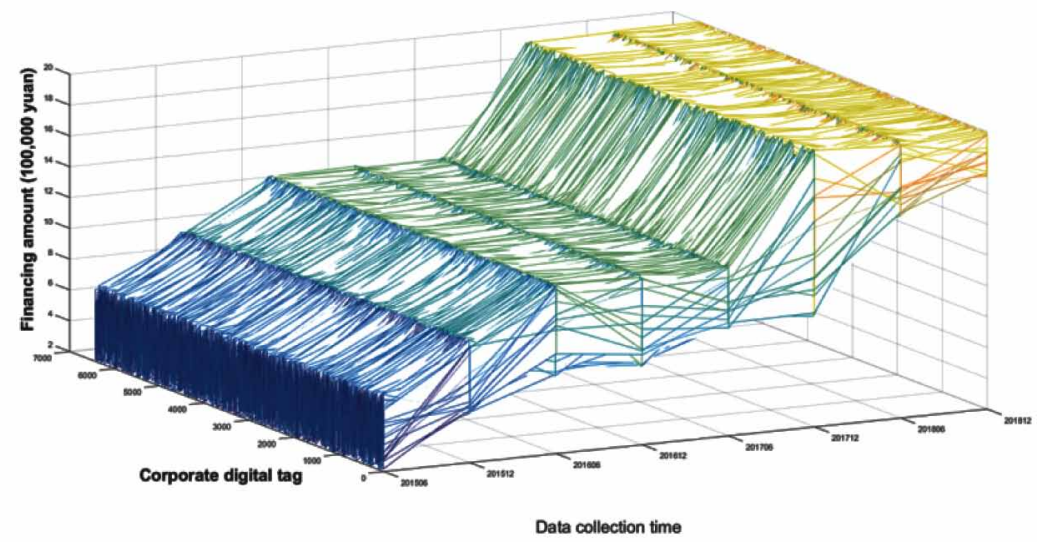




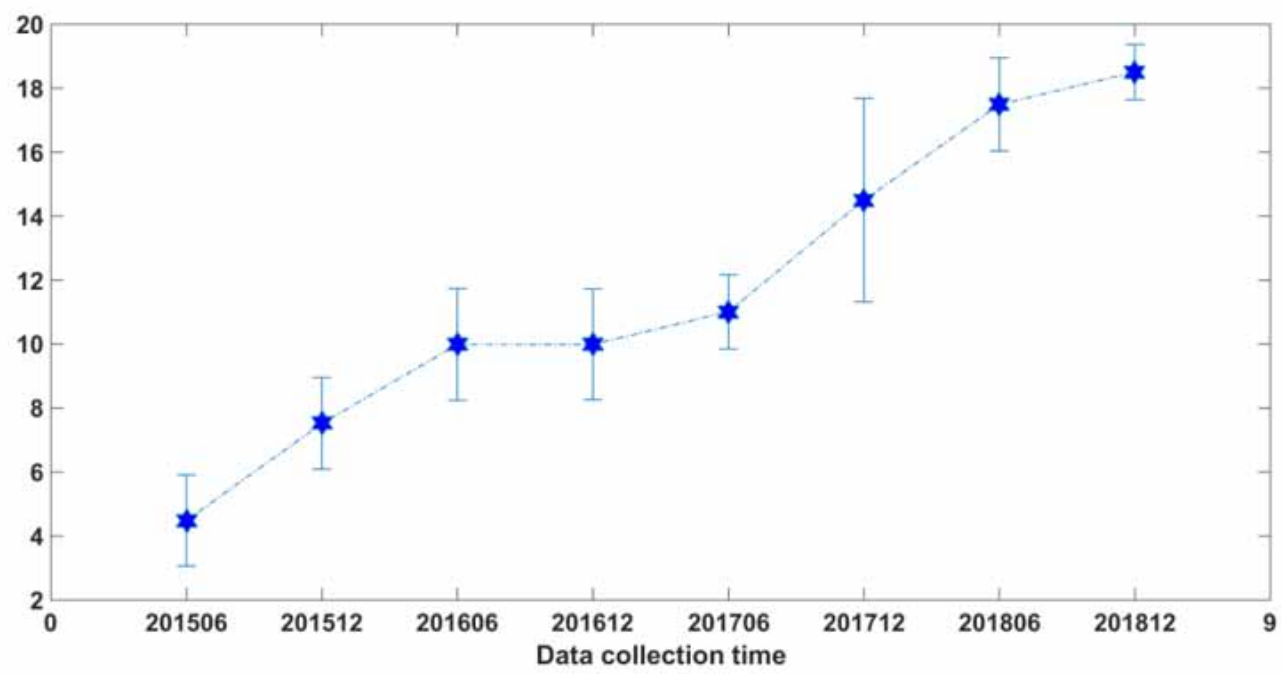

a large increase, possiblely due to the release of Internet + financial policy.E-commerce enterprises have been recognized by consumers, so more funds flow into e-commerce companies, thus causing an increase in corporate financing.

Although the amount of financing is getting bigger, corporate financing does not become easy. Figure 5 shows the mean variance of the number of financing companies. From the results of Figure 5, the average value of financing is slowly rising at the four statistical time points from 2015 to 2016, and the difference in the amount of financing is not large. The data reflect two problems: First, the financing environment was not good andthe financing of enterprises was difficult.The second is that the funds did not find a good investment channel, so the number is small, and the variance is not large.However, in December 2017, the variance was enlarged, from the original 1.7, to 3.1, and the amount of financing shows a significant increase in the mean, indicating that funds are beginning to seek breakthroughs and begin to invest heavily in certain industries.

Based on the data analysis of the effectiveness of SME financing, the survey results will measure the proportion of SME financing effectiveness and the total number of companies participating in the survey. The greater the value is, the better the financing situation of SMEs and the smaller the valueare, which also indicates that the financing of SMEs is more difficult. The result is shown in Figure 6.

Figure 6 shows the financing situation of SMEs since June 2015. It is considered that the proportion of financing difficulties is decreasing. The proportion of easy financing is slowly rising, while the proportion of enterprises with financing difficulties in general situation is always hovering around 0.5 . The proportion of enterprises without financing needs is in slow fluctuation. Through the comparative analysis of the data, we can find that the financing situation of small and medium-sized enterprises, on the whole, presents an improving development situation, but there are still quite a number of enterprises that think financing is very difficult.

\subsection{Analysis of Advantages and Disadvantages of Network Finance in Financing of Small and Medium-Sized Enterprises}

\subsubsection{Analysis of the Advantages of Network Finance}

Compared with traditional financial institutions, online finance has many advantages. Based on the analysis of the advantages of online finance, the results are shown in Figure 7. 


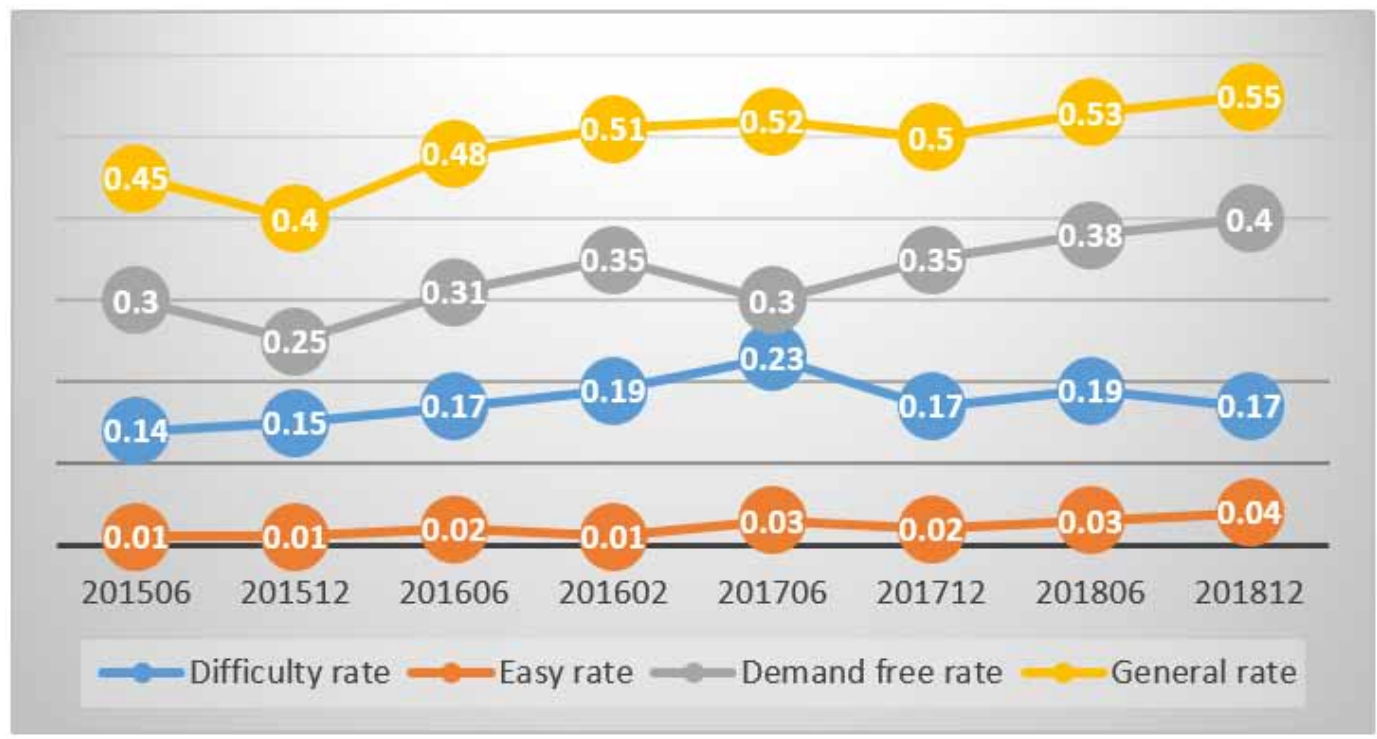

As we can see from Figure 7, online finance has three advantages, namely, high timeliness, low cost and information advantage. Small and medium-sized enterprises are flexible in their demand for funds and have high requirements for timeliness. Internet finance can break through the time and space constraints of traditional financial institutions by taking advantage of the high-speed transmission of Internet information, and the process is more efficient and approval speed is faster. Network finance

Figure 7. Analysis of advantages of network finance

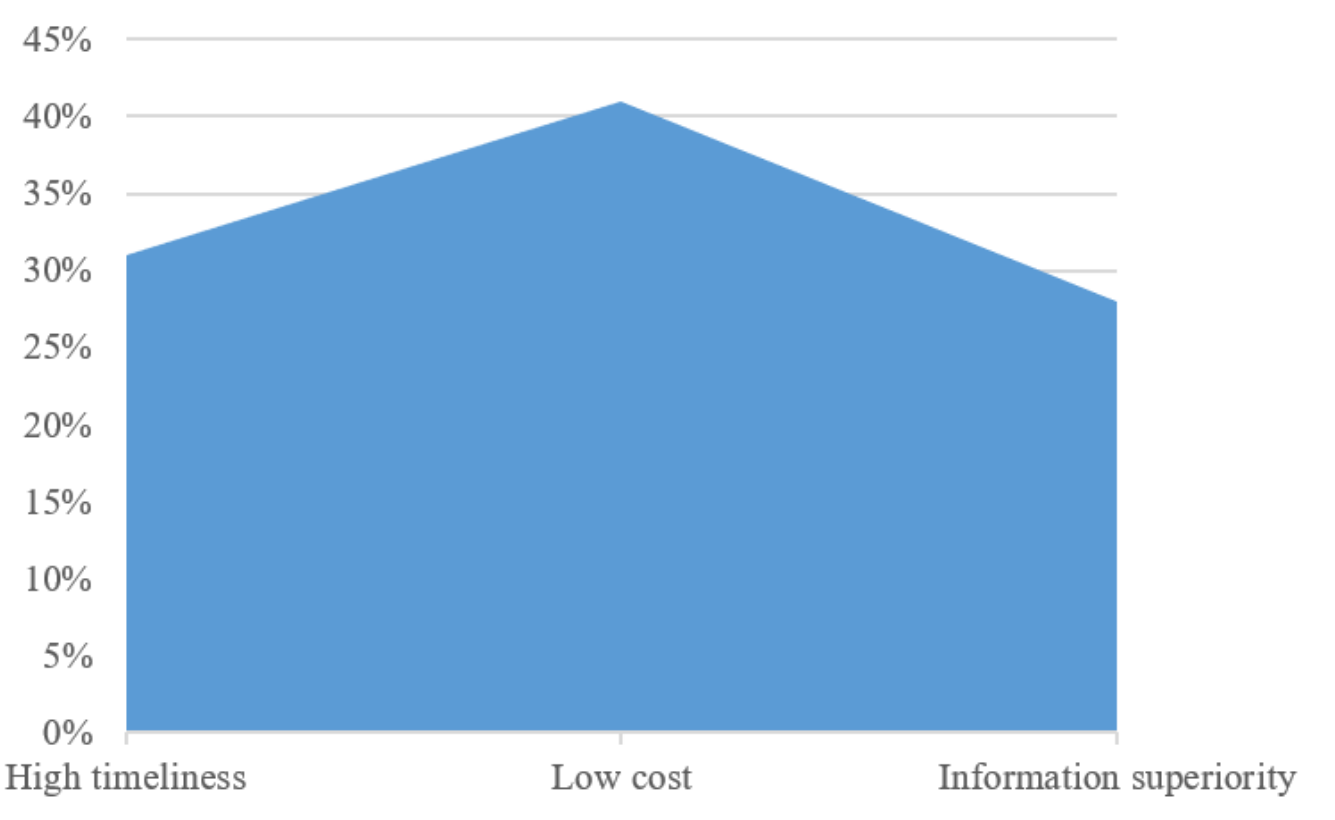




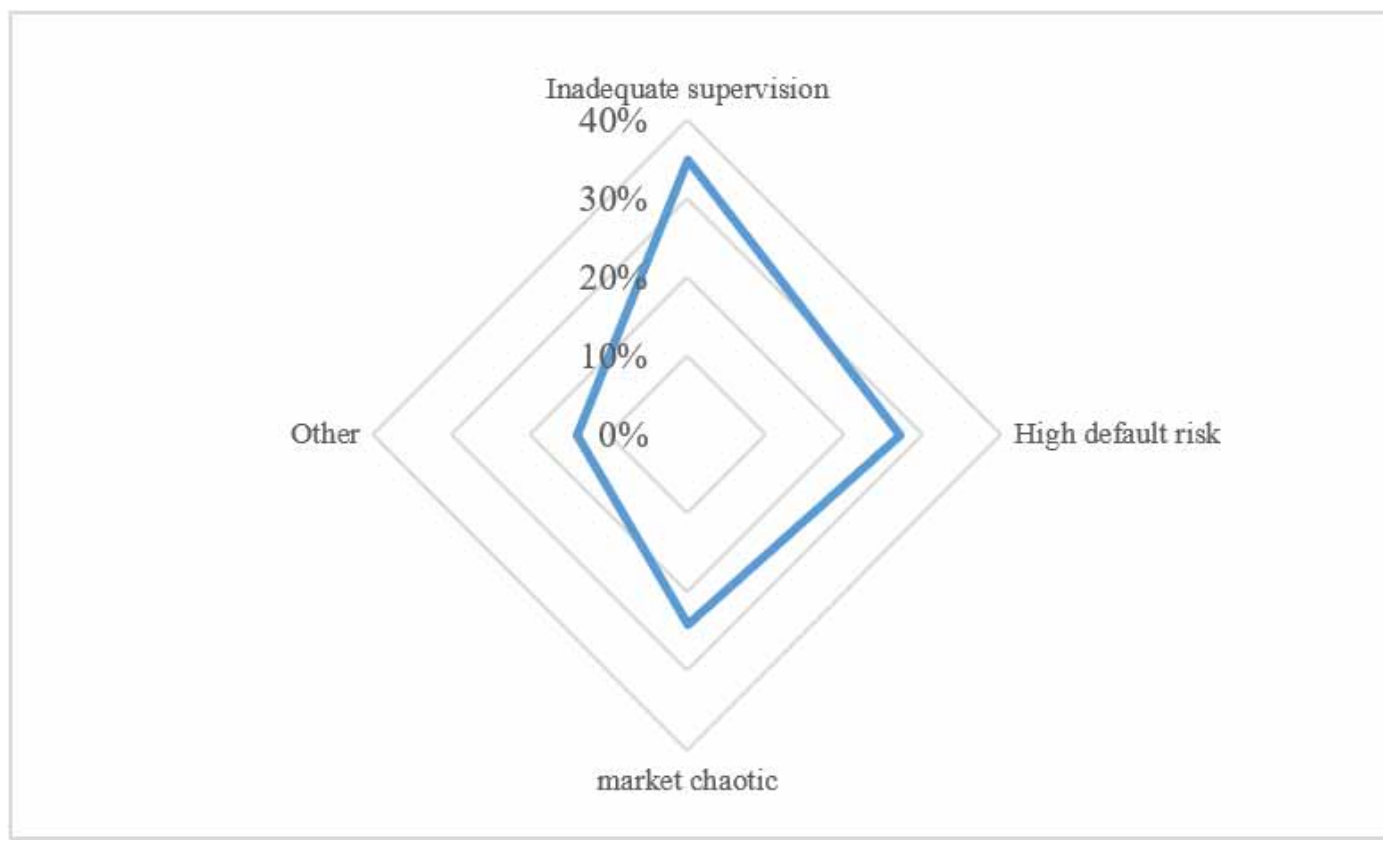

has the advantage of high timeliness. The auditing of network finance is done on the Internet, and the conclusions of big data are drawn through the collection and analysis of information. The comparative analysis of big data replaces the on-site inspection of traditional Banks, which greatly reduces the cost and has a cost advantage.The huge obstacle between SMEs and financial institutions comes from information asymmetry but mutual Internet finance can effectively avoid the occurrence of information asymmetry. Relying on the powerful functions of the Internet, Internet finance can collect information more comprehensively, facilitate the production and operation of small and medium-sized enterprises, reduce information asymmetry in the process of financing.

Internet finance has information advantages. It can be seen from the figure that among these three advantages, the most prominent advantage of network advantage is low cost, which shows that cost has a great impact on small and medium-sized enterprises.

\subsubsection{Analysis of Risk Points of Network Finance}

Although there are many advantages tonetwork finance, it is not without defects. Statistical analysis is made for the shortcomings of network finance, and the results are shown in Figure 8.

As can be seen from Figure 8, there are several obvious defects in online finance, namely, inadequate supervision, high risk of default, market chaos and other reasons. Despite the short time of network finance, its rapid and efficient development has brought a huge impact on the traditional financial industry. Many of them are financing guarantee companies that lack standardized management.These enterprises have various sources of funds and procedures for loan approval, but there is no corresponding market supervision law and market supervision subject. Inadequate supervision has become the biggest disadvantage of online finance, accounting for $35 \%$ of the four main reasons; although finance can check information through the Internet in the financing process and conduct fund audits efficiently and conveniently, the efficiency of time may also represent the lack of strict audit. Especially in the current imperfect credit system, it is difficult for Internet financial enterprises to acquire detailed situations of the lender through personal credit investigation. Enterprise 
legal persons can evade the credit investigation and verification of Internet financial enterprises by registering multiple companies or affiliated enterprises, and the relevant risks shall be borne by Internet financial enterprises. Once the enterprise defaults, Internet financial institutions also have no corresponding control means. Default risk is the second biggest defect of Internet finance, accounting for $27 \%$ of the four main reasons; Due to the regulatory loopholes in the Internet finance industry, the current Internet finance market is in chaos.Many Internet financial entities are not qualified to engage in the financial industry, and even there are enterprises only registered in the industrial and commercial departments to engage in Internet finance-related work. Without financial license, they can engage in financial work, which brings huge risks to the Internet market, and great uncertainty to the financing of small and medium-sized enterprises. Therefore, the license is necessary to be carefully identified in the financing process. Market chaos is also a defect of network finance, accounting for $24 \%$ of the four main reasons. In addition, there are some other defects in network finance, which need relevant departments to improve the corresponding system and strengthen management.

\section{CONCLUSION}

SMEs are an important part of national e-commerce economy. However, the financing difficulties for SMEs has existed for a long time. The excessive concentration of social capital and the slow development of small enterprises are detrimental to long-term economic growth.The fundamental reason for the difficulty of financing SMEs lies in the market,the information asymmetry and the moral hazard of SMEs themselves. The rapid development of network finance relies on the continuous innovation of various emerging Internet technologies, such as search engines, cloud computing, distributed storage, and social networking, such as P2P financing mode, big data financial model, and crowdfunding financing mode. The emergence of these online financial credits has improved the information asymmetry situation to a certain extent, changed the structure of social funds, and brought new financing channels and financing ideas for SMEs financing. Its convenient, efficient, flexible and low-cost features are in line with the financing needs of SMEs. To some extent, it solves the problem of financing difficulties for SMEs. However, the innovative online financing models also bring new risks. Therefore, only through continuous innovation and strengthened risk management, can we better support small and medium-sized enterprises and further promotes the progress of society.

E-commerce finance has broadened the financing channels for SMEs financing. The online loan platform based on e-commerce loans has narrowed the distance between the capital supply and demand parties, reduced the intermediate links, and reduced the distortion in the process of information transfer.Eventually, the speed and efficiency of financial communication are accelerated. Network finance has the advantages of high efficiency, low cost and information advantage, which are of great help to solve the financing difficulties of SMEs.

However, there are also shortcomings in e-commerce finance. The defects of online finance are inadequate supervision, high risk of default, market confusion and other reasons. The malpractice of network finance requires relevant departments to issue relevant policies and systems to supervise and regulate network finance as soon as possible, so as to reduce risks therein. This will not only ensure the relevant interests of SMEs, but also better protect the relevant loan platformsthemselves.

\section{ACKNOWLEDGEMENT}

This work was supported by the Humanities and Social Science Foundation of Ministry of Education of China (Grant No.19YJCZH165), and the National key R\&D Program of China: Special Project for Intergovernmental International Scientific and Technological Innovation Cooperation (Grant No. SQ2019YFE012185). 


\section{REFERENCES}

Abe, M., Troilo, M., \& Batsaikhan, O. (2015). Financing small and medium enterprises in Asia and the Pacific. Journal of Entrepreneurship \& Public Policy, 4(1), 2-32. doi:10.1108/JEPP-07-2012-0036

Ahn, J., \& Sura, S. (2020). The effect of information quality on Social Networking Site (SNS)-Based commerce: From the perspective of Malaysian SNS users. Journal of Organizational and End User Computing, 32(1), 1-18. doi:10.4018/JOEUC.2020010101

Ann, O. C., Tee, F. S., \& Nen, V. Y. (2019). A Study on Satisfaction Level Among Amateur Web Application Developers Towards Pigeon-Table as Nano Web Development Framework. Journal of Organizational and End User Computing, 31(3), 97-112. doi:10.4018/JOEUC.2019070106

Bryson, J. R., \& Daniels, P. W. (2015). Business Link, Strong Ties, and the Walls of Silence: Small and MediumSized Enterprises and External Business-Service Expertise. Environment and Planning. C, Government \& Policy, 16(16), 265-280.

Chan, K. C., Chang, C. H., \& Chang, Y. (2015). The network effects of publishing in finance. The North American Journal of Economics and Finance, 33, 305-316. doi:10.1016/j.najef.2015.06.004

Cheikh-Ammar, M., \& Barki, H. (2016). The influence of social presence, social exchange and feedback features on SNS continuous use: The Facebook context. Journal of Organizational and End User Computing, 28(2), 33-52. doi:10.4018/JOEUC.2016040103

Chen, X., Jun, H. U., \& Deng, J. (2017). Weight Correction Model of Condition Assessment for Substation Equipment Based on Multiple Linear Regression Method. High Voltage Apparatus, 53(1), 14-19.

Cunningham, M., Bock, A., Brown, N., Sacher, S., Hatch, B., Inglis, A., \& Aronovich, D. (2015). Estimating Contraceptive Prevalence Using Logistics Data for Short-Acting Methods: Analysis Across 30 Countries. Global Health, Science and Practice, 3(3), 462-481. doi:10.9745/GHSP-D-15-00116 PMID:26374805

Dankova, A., \& Telus, M. (2015). Financial Logistics of Small and Medium Sized Enterprises. Applied Mechanics and Materials, 708, 205-209. doi:10.4028/www.scientific.net/AMM.708.205

Dong, J., \& Huo, H. (2017). Identification of Financing Barriers to Energy Efficiency in Small and MediumSized Enterprises by Integrating the Fuzzy Delphi and Fuzzy DEMATEL Approaches. Energies, 10(8), 1172. doi:10.3390/en10081172

Ennouri, K., Ayed, R. B., \& Triki, M. A. et al.. (2017). Multiple linear regression and artificial neural networks for delta-endotoxin and protease yields modelling ofBacillus thuringiensis. Biotech, 7(3), 187. PMID:28664374

Fügener, S., Lang, A., \& Gaber, T. (2015). THU0166 Logistic Regression Method Identifies RA as Risk Factors for Delayed Fracture-Healing - an Update of a Single-Center Retrospective Study. Annals of the Rheumatic Diseases, 74(Suppl 2), 254.1-254.

Guo-liang, Z. (2017). Landslide susceptibility mapping using an integrated model of information value method and logistic regression in the Bailongiiang watershed, Gansu Province, China. Journal of Mountain Science, 14(2), 249-268. doi:10.1007/s11629-016-4126-9

Hamidi, H., \& Jahanshahifard, M. (2018). The Role of the Internet of Things in the Improvement and Expansion of Business. Journal of Organizational and End User Computing, 30(3), 24-44. doi:10.4018/JOEUC.2018070102

Hilsenrath, P., \& Pogue, T. (2017). Distributed dynamic capabilities in South Africa's mineral resource-finance network. Technology in Society, 49, 49. doi:10.1016/j.techsoc.2017.03.006

Khan, A. N., Cao, X., \& Pitafi, A. H. (2019). Personality traits as predictor of M-payment systems: A SEMneural networks approach. Journal of Organizational and End User Computing, 31(4), 89-110. doi:10.4018/ JOEUC.2019100105

Khanmohammadi, N., Rezaie, H., \& Montaseri, M. (2017). The application of multiple linear regression method in reference evapotranspiration trend calculation. Stochastic Environmental Research and Risk Assessment, $32(5), 1-13$.

Khashanah, K., \& Alsulaiman, T. (2016). Network theory and behavioral finance in a heterogeneous market environment. Complexity, 21(S2), 530-554. doi:10.1002/cplx.21834 
Liu, H., \& Zhang, Z. (2017). Logistic regression with misclassification in binary outcome variables: A method and software. Behaviormetrika, 44(1), 1-30. doi:10.2333/bhmk.36.1

Mansouri, A., Nazari, A., \& Ramazani, M. (2016). A Comparison of Artificial Neural Network Model and Logistics Regression in Prediction of Companies' Bankruptcy (A Case Study of Tehran Stock Exchange). International Journal of Advanced Computer Research, 6(24), 81-92. doi:10.19101/IJACR.2016.624010

Oumaya, S., \& Gharbi, L. (2017). Individual and collective absorptive capacities of new external knowledge: The case of Tunisian small and medium-sized enterprises (SMEs). International Journal of Technology Management \& Sustainable Development, 16(3), 209-227. doi:10.1386/tmsd.16.3.209_1

Pahlavan, H. A., Zahraie, B., Nasseri, M., \& Mahdipour Varnousfaderani, A. (2018). Improvement of multiple linear regression method for statistical downscaling of monthly precipitation. International Journal of Environmental Science and Technology, 15(9), 1897-1912. doi:10.1007/s13762-017-1511-z

Park, J. H. (2018). Open innovation of small and medium-sized enterprises and innovation efficiency. Asian Journal of Technology Innovation, 26(2), 1-31. doi:10.1080/19761597.2018.1496796

Piña-Monarrez, M. R., \& Ortiz-Yañez, J. F. (2015). Weibull and lognormal Taguchi analysis using multiple linear regression. Reliability Engineering \& System Safety, 144(5), 244-253. doi:10.1016/j.ress.2015.08.004

Rouhani, S., Ashrafi, A., Ravasan, A. Z., \& Afshari, S. (2018). Business intelligence systems adoption model: An empirical investigation. Journal of Organizational and End User Computing, 30(2), 43-70. doi:10.4018/ JOEUC.2018040103

Sang, B. H., Kwon, S., \& Yun, J. (2017). The effects of policy funds on the financing constraints of small- and medium-sized enterprises in South Korea. Applied Economics Letters, 24(10), 699-702. doi:10.1080/135048 51.2016.1223804

Strzębicki, D. (2015). The Development of Electronic Commerce in Agribusiness - The Polish Example. Procedia Economics and Finance, 23, 1314-1320. doi:10.1016/S2212-5671(15)00573-0

Wang, X., Ding, H., \& Yi, H. U. (2017). The evaluation of financing efficiency for China's small and mediumsized enterprises based on DEA model. Xitong Gongcheng Lilun Yu Shijian/System Engineering Theory \& Practice, 37(4), 865-874.

Xiang, D., \& Worthington, A. C. (2017). The impact of government financial assistance on the performance and financing of Australian SMEs. Accounting Research Journal, 30(4), 447-464. doi:10.1108/ARJ-04-2014-0034

Yoon, H. S., \& Occeña, L. G. (2015). Influencing factors of trust in consumer-to-consumer electronic commerce with gender and age. International Journal of Information Management, 35(3), 352-363. doi:10.1016/j. ijinfomgt.2015.02.003

Ping Wang received a PhD degree in Industrial Information System from Seoul National University of Science and Technology in August 2015. Dr. Ping Wang is currently Assistance Professor in School of Economics and Management, Weifang University of Science and Technology, China. His research interests include internet finance, technology financial innovation, pension financial innovation and industrial information system. He has published more than 10 papers at different journals. He is now presiding a project of the National Key R\&D Program of China: Special Project for Intergovernmental International Scientific and Technological Innovation Cooperation, and also presided a project of the Humanities and Social Science foundation of Ministry of Education of China, and many other provincial-level projects in China.

Wei Han (Corresponding Author) is currently an Assistance Professor in Henan Agricultural University, China. And he is also a Ph.D. candidate at the School of Economics and Management, Southwest Jiaotong University, China. His research interests include internet finance, behavioral finance, pension finance innovation and accounting information system. He has published in Electronic Commerce Research, Asian Economic Journal and China Finance Review International, and serves as a peer reviewer for international journals such as Electronic Commerce Research, Computational Economics, Asian Economic Journal, and Cluster Computing. 